\title{
SISTEMA PRISIONAL BRASILEIRO FRENTE ÀS DIFICULDADES ENCONTRADAS PARA UM NOVO MEIO VIÁVEL DE À APLICAÇÃO DE SANSÕES PENAIS
}

\author{
Kaique Daniel dos Santos Vigetta \\ Universidade do Oeste Paulista - UNOESTE, Curso de Direito, Presidente Prudente, SP. E-mail: \\ kaiquevigetta@hotmail.com
}

\begin{abstract}
RESUMO
O presente artigo refere-se ao atual sistema prisional do Brasil, à violação dos direitos humanos para com os detentos e as dificuldades encontradas claramente pelo governo em administrar tais estruturas prisionais. Mostrara as dificuldades encontradas tanto pelos governantes e administradores quanto pelos detentos na ressocialização. Trará possíveis soluções para o abatimento das dificuldades encontradas até o presente momento desta crise que vem crescendo rapidamente.
\end{abstract}

Palavras chaves: Sistema prisional; Administração pública brasileira.

\section{BRASILIAN PRISON SYSTEM FACING THE DIFFICULTIES TO A NEW MEDIUM VIABLE OF THE APPLICATION OF CRIMINAL SANCTIONS.}

\begin{abstract}
This article refers to the current prison system in Brazil, the violation of human rights to the detainees and the difficulties found clearly by the Government in administering such prison structures. It showed the difficulties encountered by both the rulers and administrators and the detainees. Treats possible solutions to the reduction of the difficulties encountered until now of this crisis that has been growing rapidly.

Keywords: Prison system; Brazilian public administration.
\end{abstract}

\section{INTRODUÇÃO}

Nas ultimas décadas a população carcerária do Brasil tem apresentado um aumento considerável, sem que o número de vagas disponíveis para os detentos acompanhasse a necessidade prisional do país. 0 alto número de reclusos em Penitenciarias Estaduais, Federais e até mesmo em Cadeias Públicas vem causando grande preocupação no poder público e na população em geral, dada a superlotação dos estabelecimentos prisionais e a majoritária precariedade destas estruturas.

A falta de uma administração adequada, somada a superlotação das prisões tem causado inclusive problemas de ordem sanitária na maioria dos estabelecimentos prisionais, fazendo com que a penitenciaria se configure em um simples local de isolamento social, inexistindo, na maioria dos casos o mínimo alcance da finalidade reintegradora da reprimenda. 0 presente artigo tem como objetivo contribuir com o debate em relação aos principais problemas enfrentados por nosso sistema prisional, bem como, objetiva aventar eventuais medidas para estes sejam ao menos minimizados.

\section{METODOLOGIA}

Para a execução deste artigo houve um levantamento por meio bibliográfico exploratório, pesquisa em mídias em nexo com os poderes do Estado e pronúncias verídicas de membros do parlamento, além das leis positivadas, para uma análise e obtenção de resultados mais seguros e completos dos fatos aqui expostos. 


\section{DISCUSSÃO}

FINALIDADE DA PENA PRIVATIVA DE LIBERDADE

Pesquisas nos mostram que no início, onde se notou os primeiros vestígios de um estado de direito, diz que a finalidade da pena de correção a um autor de delito, era de punir como forma de vingança, onde esses criminosos eram levados a pagar por seus crimes recebendo penas rigorosamente cruéis como a morte, através da forca, açoitamento, afogamento etc.

A evolução dos sansões punitivas no direito penal desde aquela época até os dias de hoje, nos mostra claramente que não conseguiu evoluir-se assim como o tempo, as formas para corrigir o réu.

Os primeiros vestígios de aplicação da pena privativa de liberdade no mundo foram notados no meio da idade média, segundo o doutrinador Sérgio Salomão Shecaira em seu livro teoria das penas; ele explica que "A igreja do século IV para punir os clérigos faltosos, usava aplicar como penalidade a reclusão em celas ou a internação em mosteiros" resguardando o réu para uma punição logo após mais severa.

Com o surgimento da idade moderna logo após o período feudal, surgiram com a evolução diversas guerras religiosas e a pobreza se alastrou por todo o continente europeu, consequentemente assim, houve o aumento evidente de delinquentes e com sigo, a necessidade do Estado de proteger seus cidadãos e seus bens jurídicos.

Brevemente falando a pena formalmente hoje no nosso país, e dada a alguém que cometeu um fato típico, ilícito e culposo; usada como uma forma de retribuir o ato ilícito no âmbito penal e readaptar o réu para a volta à vida em sociedade.

Hoje no Brasil a pena privativa de liberdade aplicada ao crime é adotada como uma forma retributiva, preventiva e reeducativa: 10 punir o fato e não o autor, aplicando a sansão como forma de retribuir o mal com o mal; 2응 prevenir que tais fatos se repitam, mas especificamente de duas formas, a prevenção geral e a especifica: a prevenção geral mostra que o fundamental é intimidar o cidadão com a aplicação penal para poder prevenir que alguém cometa algum tipo de crime, através da ameaça; já a prevenção especial é algo que não se impõe ao coletivo da sociedade, mas ao individual impondo-se a aquele que já cometeu o ilícito, através da ressocialização, para que o mesmo não volte a praticar crimes; e por último e 3 , reeducar o detento, o ressocializando para que ele saia da prisão um cidadão correto perante as normas da sociedade tendo a oportunidade dada pelo Estado de se reintegrar novamente, e assim, diminuir as incidências de pratica de crimes no país.

\section{A Situação do Sistema Prisional Brasileiro}

Segundo levantamentos, atualmente o Brasil possui aproximadamente 726.000 presos para as 368.000 vagas distribuídas em suas 1.4 mil unidades de prisões pelo país. Cerca de $94 \%$ deles são de sistema penitenciário estadual, $5 \%$ de prisões em delegacias, cadeias ou secretarias de segurança e $0,8 \%$ de unidades de penitenciárias federais de segurança máxima. Mais da metade são de jovens entre 18 e 24 anos e $64 \%$ negros, segundo o levantamento Nacional de informação penitenciarias divulgada em (08/12/2016).

Dados que $40 \%$ dos presos são provisórios, ou seja, que não tiveram uma condenação ainda, pois o sistema demora meses e até anos para dar um julgamento ao réu, pela escassez de juízes, à má administração do gerenciamento de governo e a falta de implantação de outros meios como a aplicação de intervenções mínimas, tratada no direito penal como uma forma de trazer a solução de que se a pena privativa de liberdade fosse usada somente para inflações que realmente necessite como os delitos mais graves em que não há solução para a proteção do bem jurídico, não haveria tantos detentos, assim, diminuindo a superlotação carcerária e melhorando até possivelmente a situação econômica do país em relação ao sistema jurídico e demais investimentos do Estado.

Segundo a atual presidente do STF, um preso hoje custa 13 vezes mais que um estudante de ensino médio no país.

Enquanto que o estudante custa $\mathrm{R} \$ 2,2$ mil por ano, um preso custa $R \$ 2,4$ mil em média por mês, o que de fato mostra a urgência de serem elaboradas e aplicadas mudanças estruturantes no Brasil. Tal informação faz-nos pensar o que realmente é feito com o dinheiro encaminhado às prisões se em muitas delas, as situações carcerárias ainda hoje são precárias e inacreditáveis.

Reportagens e documentários mostra que a superlotação de detentos traz aos aprisionados situações que nos fazem ver de fato a falta de respeito com os direitos humanos dados a cada ser humano no momento do seu 
nascimento dirigido na constituição pelo governo, na falta de espaço das celas e falta higiene delas; nos maus tratos; na qualidade de alimentação precária; na propagação de doenças, e inclusive sexuais entre os presos e na falta de higiene dos corredores e das cozinhas propagando ainda mais os vírus de doenças contagiosas que se transferem de detentos para seus visitantes e até mesmo para os agentes penitenciários que estão ali somente para colocar em pratica as normas do governo.

Além de doenças físicas, essas causas trazem enfermidades também ao sistema psicológico como a demência e a depressão, em que leva muitas vezes aos suicídios dos detentos, assassinatos e as notórias rebeliões em presídios feitos pelos presidiários, como um meio de protesto à forma de gerenciamento do Estado voltada aos presídios, pelos meios em que a administração usa para tratar dos detentos que vivem lá.

Em bora a falta de segurança nos pavilhões traz inúmeras mortes causadas por rebeliões entre facções, $62 \%$ delas segundo o Ministério da Justiça, é provocada por doenças como a sífilis, a tuberculose e o HIV.

Baratas andam pelas tubulações de água em que se dizem potável para os presidiários e ratos trafegam entre o convívio dos presos transmitindo sarnas e enfermidades contagiosas trazida dos esgotos. As celas que deviam ter no mínimo seis metros quadrados e serem salubres de acordo com a Lei de Execução Penal (LEP), em muitos lugares não existem, dificultando ainda mais a situação, pois são colocados nesses espaços mais presos do que o limite possível que podem ser suportados, tendo os presidiários que brigarem entre si para obterem lugar e espaço.

A falta de saneamento básico não reeduca e não ressocializa o preso, mas viola os direitos humanos, a e dignidade que the são inerentes, os revoltando. Criando as verdadeiras escolas do crime.

Todo este contexto nos obriga de fato a pensar em que tipo de Ex-presidiário queremos ter para o nosso convívio em sociedade. Um perigoso ou um reabilitado?!

A prisão deveria ser uma forma de punir e ressocializa-los, de dá-los através do apoio do governo e da sociedade que clama cada vez mais pelas prisões, a oportunidade de se reintegrarem ao corpo social e a chance de mudança para fazêlos escolherem um futuro diferente e melhor para eles e seus entes.
Como a maior dificuldade de ingressar na sociedade novamente, se encontra no mercado de trabalho onde é a principal barreira após cumprirem sua sentença e a principal forma de sobrevivência, porque se não trabalha não tem dinheiro, se não tem dinheiro não tem alimento e se não tem alimento, morre, tal situação acaba fazendo com que muitos destes, não tendo uma maneira de se manterem e manterem suas famílias, voltem à vida do crime para sobreviverem.

Tal fato trazido da triste realidade não educativa brasileira. Assim como Zaffaroni citou em seu livro, em busca das penas perdidas, "A dor e a morte que nossos sistemas penais semeiam estão tão perdidas, que o discurso jurídico-penal não pode ocultar seu desbaratamento valendo-se de seu antiquado arsenal de racionalizações reiterativas: achamonos em verdade, frente a um discurso que se desarma ao mais leve toque com a realidade".

\section{POSSÍVEIS SOLUÇõES ATRAVÉS DE SUGESTÕES PARA O COMBATE DA ATUAL SITUAÇÃO CARCERÁRIA.}

As formas de trazer falência às prisões brasileiras seria a atuação de penas alternativas como o aumento de multas, em que esses valores poderiam ser usados revertidos aos detentos aprisionados por crimes graves, às reformas carcerárias e à educação de crianças e adolescentes da sociedade, já que as grandes maiorias dos detentos não tiveram a oportunidade de estudo e cresceram sem apoio para aprender sobre o correto e o errado imposto pela moral da sociedade; Serviços comunitários em prol da comunidade; e a aplicação de mais privações de direitos ou de monitoramento através de tornozeleiras eletrônicas assim como propõe o artigo 318 do código processual penal, de troca de prisão preventiva por domiciliar, que reduz a média de um preso de $\mathrm{R} \$ 2,4$ mil ao mês para $\mathrm{R} \$ \mathbf{2 3 0}$ reais, e que no ultimo ano preveniu que 140 mil réus provisórios ingressassem nas cadeias.

O Governo do Brasil deveria aplicar normas baseadas em sua própria situação gerada pela sociedade e não por cópias feitas de outros Estados, precisamos de seres inteligentes na administração do nosso país para derrubar tais crenças perturbadoras que não beneficia a ninguém e não de seres corruptos que não se preocupam realmente com a realidade da nossa sociedade.Declarações através das mídias não 
colocam a pratica que precisamos ter nas ruas, somente ilude aos menos afortunados de inteligência e gera informação suja ao país, fazendo lhes acreditarem que algo está sendo feito. Mentes vazias. Para o governo quanto menos pessoas entenderem sobre tais assuntos melhor. Geração que acredita estar avançando, mas boa parte esta cega.

Uma sociedade que só pensa no agora, influenciada pela mídia abusiva e ignorante no que se trata de noticiar crimes, não olham para o futuro e pensam que se não tivermos expresidiários ressocializados, haverá ilicitudes cada vez mais graves de pessoas contra pessoas. Temos que ajudar a corrigir o nosso país através de iniciativas populares que nos são de direitos; se a mídia desse cada vez mais a informação que precisamos saber dos nossos direitos, o cenário do país poderia ser outro.

\section{CONSIDERAÇÕES FINAIS}

É torpe acreditar que formas tão severas como à falta de dignidade dada pela omissão dos poderes de um país, ajudará tanto no convívio e na vida de um ser dentro, como em um de fora das penitenciarias. Devemos pensar nas consequências que nossas decisões para com os presos irão causar e custar a nossa sociedade como um todo, às nossas famílias e aos seus descendentes no futuro não tão longe deste presente. Um Estado democrático de poder que caminha para tal situação, está prestes a perder total controle social sobre a realidade, que não prejudica somente os presos, mas também a nós.

\section{REFERÊNCIAS}

SHECAIRA, Sérgio Salomão. Teoria da pena. Finalidades, direito positivo, jurisprudência e outros estudos de ciência criminal. São Paulo: Editora Revista dos Tribunais, 2002, p. 31. 